This is the final peer-reviewed accepted manuscript of:

Guarini, A., Bonifacci, P., Tobia, V., Alessandroni, R., Faldella, G., \& Sansavini, A. (2019). The profile of very preterm children on academic achievement. A crosspopulation comparison with children with specific learning disorders. Research in Developmental Disabilities, 87, 54-63.

The final published version is available online at:

https://doi.org/10.1016/j.ridd.2019.02.001

Rights / License:

The terms and conditions for the reuse of this version of the manuscript are specified in the publishing policy. For all terms of use and more information see the publisher's website.

This item was downloaded from IRIS Università di Bologna (https://cris.unibo.it/)

When citing, please refer to the published version. 


\title{
The profile of very preterm children on academic achievement. A cross-population comparison with children with specific learning disorders
}

\author{
Annalisa Guarini ${ }^{\mathrm{a}, *}$, Paola Bonifacci ${ }^{\mathrm{a}}$, Valentina Tobia ${ }^{\mathrm{b}}$, Rosina Alessandroni ${ }^{\mathrm{c}}$, \\ Giacomo Faldella ${ }^{\text {c,d }}$, Alessandra Sansavini ${ }^{\mathrm{a}}$ \\ ${ }^{a}$ Department of Psychology, University of Bologna, Italy \\ ${ }^{\mathrm{b}}$ Department of Psychology, University of Milano-Bicocca, Italy \\ ${ }^{\mathrm{c}}$ Neonatal Unit, St. Orsola-Malpighi University Hospital, Bologna, Italy \\ ${ }^{\mathrm{d}}$ Department of Medical and Surgical Sciences, University of Bologna, Italy
}

\section{A R T I C L E I N F O}

No. of reviews completed is 2

Keywords:

Preterm birth

Literacy

Maths

School age

Specific learning disorders

\begin{abstract}
A B S T R A C T
Background: Very preterm (VPT) children showed delays in reading, spelling and maths, but their academic achievement profile is not clearly understood.

Aims: VPT children were compared with children with specific learning disorders (SLD) and typically developing (TD) children on academic achievement, considering cognitive and linguistic phenotypic markers. A learning profile analysis was also performed.

Methods: We included 170 10-year old monolingual Italian-speaking children (37 VPT, 28 SLD, $105 \mathrm{TD})$ assessing cognitive, linguistic and academic skills.

Results: On academic achievements VPT children fell behind TD peers in some reading (text speed, comprehension), spelling (non-word), and math (number knowledge, written calculations and problem-solving) tasks. SLD children underperformed in all academic tasks with respect to VPT and TD peers. Concerning cognitive and linguistic phenotypic markers, compared to TD peers, VPT children showed lower scores in verbal IQ and phonological fluency, SLD children in phonological processing and rapid automatized naming. VPT children showed a higher rate of atrisk performance in reading compared to TD group, but a minor percentage of impaired profiles and comorbidity among learning areas compared to SLD group.

Conclusions and implications: The academic achievement profile of VPT children shows persistent delays, but it differs to that of SLD children, since delays are less widespread and severe, and differences were found in phenotypic markers and comorbidity. Follow-up programs and effective interventions are needed for VPT children.
\end{abstract}

\section{What this paper adds}

Very preterm birth (VPT) affects academic achievement. However, previous studies have only compared VPT children with typically developing (TD) peers, using composite measures for reading, spelling and maths. By contrast, a comparison with another population with atypical development in academic-related skills can be useful to understand the academic achievement profile of

Abbreviations: VPT, very preterm children; SLD, specific learning disorders; TD, typically developing

* Corresponding author at: Department of Psychology, University of Bologna, Viale Berti Pichat 5, 40127 Bologna, Italy.

E-mail address: annalisa.guarini@unibo.it (A. Guarini). 
VPT children, identifying similarities and differences in specific components. The present study compared for the first time the academic achievement profile of VPT children with that of children with Specific Learning Disorders (SLD) and TD children. Our findings pointed out an atypical academic achievement profile in VPT children, since residual delays in reading, spelling and math were described at the end of primary schools with some abilities preserved and other delayed (i.e., reading text speed, reading comprehension, non-word spelling, number knowledge, written calculations and problem-solving). The academic achievement profile of VPT children differed from that of SLD children. First, impairments were less widespread, involving only some of the above mentioned skills, and less severe (i.e., mean scores were comprised within -1 SD). Secondly, cognitive and linguistic phenotypic markers were different in these populations, suggesting different processes underlying delays in academic achievement. Third, a higher rate of SLD children fell into the impaired category, with comorbidity among learning areas, whereas VPT children showed a higher proportion of at-risk performance in reading. Specific follow-up programs and effective interventions are needed for VPT children, considering their atypical development in academic achievement.

\section{Introduction}

Several studies have investigated the effect of very preterm birth (VPT, gestational age $<32$ weeks of gestation) on academic achievements pointing out some concordant findings, as well as a number of lines of investigation to follow. As suggested by reviews and meta-analyses, VPT birth affects literacy and maths at school age (Aarnoudse-Moens, Weisglas-Kuperus, van Goudoever, \& Oosterlaan, 2009; Moreira, Magalhães, \& Alves, 2014; Sansavini, Guarini, \& Caselli, 2011; Twilhaar, de Kieviet, Aarnoudse-Moens, van Elburg, \& Oosterlaan, 2018). VPT children scored 0.48 SD lower on reading, 0.76 on spelling and 0.60 on math tests (AarnoudseMoens et al., 2009). Text comprehension was also affected in VPT children scoring 0.57 SD lower than their peers (Kovachy, Adams, Tamaresis, \& Feldman, 2015).

Delays have been observed starting from kindergarten (Shah, Kaciroti, Richards, Oh, \& Lumeng, 2016) and persisting into primary (Taylor et al., 2016) and secondary school (Aarnoudse-Moens et al., 2009; Twilhaar, de Kieviet et al., 2018). Thus, the effect of preterm birth continues across development up to adolescence suggesting an atypical developmental trajectory (Sansavini et al., 2011) with lifelong consequences and implications, such as a greater need for educational support and higher rates of grade repetition (Aarnoudse-Moens, Oosterlaan, Duivenvoorden, van Goudoever, \& Weisglas-Kuperus, 2011; Twilhaar, de Kieviet et al., 2018).

Even if we can assume that preterm birth affects academic achievement from kindergarten up to adolescence, several issues have not been deeply explored and questions are still open with preliminary contrasting results. First, previous studies have compared the profile of VPT children in academic achievement with that of typically developing (TD) children. However, as suggested by D'Souza, Booth, Connolly, Happé, and Karmiloff-Smith (2016), going beyond unique TD comparisons, cross-population studies, including different atypical populations, could be more useful for understanding the profile of a population with atypical development by identifying similarities and differences across disorders. Starting from this consideration, we intended to compare VPT children with children with specific learning disorders (SLD), since these populations shared three characteristics. First, as for VPT children, SLD children show delays in reading, spelling and math (American Psychiatric Association, 2013). Secondly, in both populations impairments in academic achievement might occur in the absence of intellectual disabilities, that is, within an average intellectual functioning. Indeed, even if lower IQ scores were reported in VPT children (0.86 SDs than full-term children, Twilhaar, Wade et al., 2018), mean IQs were comprised in a normal range. In SLD children the IQ is in the normal range by diagnostic definition (American Psychiatric Association, 2013). Third, some studies have revealed that delays in academic achievement persisted also controlling for general IQ scores both in VPT children (Guarini et al., 2014; Simms, Cragg, Gilmore, Marlow, \& Johnson, 2013) as well as in SLD children (e.g., Andersson, 2010; Ghelani, Sidhu, Jain, \& Tannock, 2004). Concerning the comparison between VPT and children with SLD, some preliminary suggestions have been pointed out by two studies investigating the mathematical domain in VPT children. The first one suggested that preterm birth did not increase the risk of dyscalculia (i.e., the specific learning disorder affecting mathematics; Price \& Ansari, 2013), but lower gestational age was associated with a higher risk of mathematical impairments (Jaekel \& Wolke, 2014). Another study suggested that math difficulties in VPT children were different from those of children with dyscalculia, since working memory and visuo-spatial processing were affected, but not numerical representation (Simms et al., 2015). However, both studies did not directly collect data from SLD children.

A second limitation of the existing research was the prevalent use of composite measures for reading, spelling and maths, without describing which components were affected (Simms et al., 2013; Twilhaar, de Kieviet et al., 2018). The few studies, that deepened the profile of learning achievements within some specific domains, highlighted interesting patterns of results. For example, in reading tasks VPT children were accurate but slower than their peers at 8 years, whereas they made more errors in spelling, with differences across measures of word, non-word and sentence reading (Guarini et al., 2010). Concerning maths, VPT children aged 8-10 years showed poorer counting skills and used less sophisticated strategies in solving arithmetic problems, whereas no delay was found in other skills (number fact knowledge, number line estimation, symbolic magnitude comparison, Simms et al., 2015). These promising results suggested the need to deepen this issue in order to describe the academic achievement profile of VPT children as well as to plan focused intervention to improve the delayed skills.

Third, the literature offers contrasting results regarding domains that are more affected in VPT children. Some studies suggested that delays of VPT children were more pronounced in maths than in literacy (Chyi, Lee, Hintz, Gould, \& Sutcliffe, 2008; Taylor, Espy, \& Anderson, 2009), whereas others revealed similar weaknesses in both domains (Aarnoudse-Moens et al., 2009). In addition, few studies have analyzed the comorbidity among delays in reading, spelling and maths in VPT children, showing high rates of combined learning delays across multiple curriculum areas (Pritchard et al., 2009). A high risk for comorbidity was recently described in 
extremely preterm children (gestational age $<26$ weeks) suggesting that isolated cognitive and learning delays were uncommon (Johnson et al., 2016). These results revealed that comorbidity among learning disabilities was poorly understood, pointing out the need for further studies on this topic in VPT children.

Based on these questions the present study compared, for the first time, the academic achievement profile of VPT children with that of SLD and TD children, analyzing different components of reading, spelling and maths in the three groups. To better describe the origin of academic delays, we also analyzed cognitive skills (IQ scores) and specific skills that are considered phenotypic markers of learning delays (i.e., attention, working memory, phonological awareness, fluency, and rapid automatized naming-RAN) both in VPT (Guarini et al., 2010; Loe et al., 2012; Rose, Feldman, \& Jankowski, 2011; Simms et al., 2015) and SLD children (Price \& Ansari, 2013; Snowling, 1998). We hypothesized that VPT children are characterized by an atypical pathway with an academic achievement profile different from that of SLD children, due to the different aetiological origins of delays in these two populations. We expected VPT children having less advanced literacy and math skills than their TD peers, but with less severe delays and different cognitive and phenotypic markers compared with SLD children.

Second, we aimed at investigating the rate of at risk and learning impaired children across the three groups. We performed a profile analysis comparing the percentages of VPT, SLD and TD children classified as impaired ( $\leq 2$ SD), at risk (between -2 and -1 SD) or in the average range ( $\geq 1 \mathrm{SD}$ ) for each domain (reading, spelling and maths). We expected a higher percentage of at risk VPT children and of impaired SLD children. We also analysed the comorbidity among reading, spelling and math impairments, comparing VPT and SLD children.

\section{Method}

\subsection{Participants}

One hundred and seventy monolingual Italian-speaking children were included: 37 VPT, 28 SLD and 105 TD children. All children had no major cerebral damage, no congenital malformations, no visual or hearing impairment, no intellectual disabilities, and no socio-economic disadvantage.

VPT children (15 females) were born in 2003 and 2004 at the Neonatology Unit of the University Hospital of Bologna. Their mean chronological age was 10 years and 4.5 months (SD = 7.5 months). VPT children were included if, at birth, had a gestational age $<32$ weeks of gestation. The mean gestational age of the VPT sample was 29.2 weeks (SD $=1.7$, for additional description see Table S1, online Supporting information).

SLD children (15 females, mean chronological age: 10 years and 2.3 months, SD $=8.1$ months) were recruited at LADA laboratory, University of Bologna. They were included if they were born at term ( $\geq 37$ weeks of gestation) and had received a diagnosis of SLD in the last 2 years. The diagnosis was defined on the basis of a full neuropsychological assessment according to the International Classification of Diseases (ICD-10 code: F.81) (World Health Organization, 2016) and standard Italian criteria (Consensus Conference, 2010), with scores below 2 SDs in standardized tests assessing reading, spelling or maths.

All TD children ( 54 females) were included if they were born at term ( $\geq 37$ weeks of gestation) and had no diagnosis of SLD. They were recruited from several Primary Schools in the same geographical area as the clinical groups (mean chronological age of assessment: 10 years and 3 months, $S D=6.4$ months).

The three groups were comparable in terms of age of assessment and gender. In addition, all children in the three groups were comparable for the following social background characteristics: area of residence (Bologna city); educational exposure (only public schools were involved); linguistic and cultural context (all children were monolingual with both Italian parents).

\subsection{Procedure}

The assessment of VPT and SLD children was performed in a quiet room at the University; TD children were assessed in a quiet room at their school.

The study protocol met the ethical guidelines for protection of human participants and received formal approval by the local Ethical Committee (Independent Ethics Committee of the University Hospital of Bologna "S.Orsola-Malpighi"). The parents of the children released their informed written consent for participation to the study.

\subsection{Materials}

\subsubsection{IQ, cognitive and language phenotypic markers}

2.3.1.1. IQ. The Italian version of the "Kaufman Brief Intelligence Test, Second Edition" (K-BIT-2, Bonifacci \& Nori, 2016) was administered. The verbal scale contains two item types: verbal knowledge (requiring the child to select the picture considered to best illustrate the meaning of the word presented orally by the examiner) and riddles (requiring the child to provide the word that best fits with some adjectives or functions of an object/concept). The non-verbal subscale is a matrices subtest. Three indexes were provided: Composite score (C-IQ), Verbal score (V-IQ) and Non verbal score (NV-IQ).

2.3.1.2. Attention. The sustained attention task from the Leiter International Performance Scale-Revised (Roid \& Miller, 2002) was administered. Children were asked to cross out as many of the objects matching the target as possible, without accidentally crossing out any other objects, given a limited amount of time. The number of correct responses was scored, according to the manual. 
2.3.1.3. Digit span. The Digit Span test from Wechsler Intelligence Scale for Children-III (WISC-III, Italian adaptation, Orsini \& Picone, 2006) was administered. The child was asked to listen and repeat 3-9 digits forwards and 2-9 digits backwards. The sum of correct sequences of digits was computed.

2.3.1.4. Fluency. Fluency tests from the NEPSY-II (Italian version, Urgesi, Campanella, \& Fabbro, 2011) were administered. Concerning semantic fluency, the child was asked to produce as many words as possible in $60 \mathrm{~s}$ for the categories Animals, Food and Drinks. With respect to phonological fluency, the child was asked to produce as many words as possible in $60 \mathrm{~s}$ starting with the phoneme /s/ and /f/, respectively. The numbers of words for semantic and phonological fluency were scored.

2.3.1.5. Phonological processing. The phonological processing test from the NEPSY-II (Italian version, Urgesi et al., 2011) was administered. The child was asked to create a new word by omitting or substituting a syllable or a phoneme. The number of correct responses was computed.

2.3.1.6. RAN. In the rapid automatized naming task (De Luca, Di Filippo, Judica, Spinelli, \& Zoccolotti, 2005) the child named aloud matrices of objects. Correct responses and time were scored.

\subsubsection{Literacy and numeracy skills}

2.3.2.1. Reading. To assess decoding skills, children were asked to read aloud a list of words (112 words, DDE-2, Sartori, Job, \& Tressoldi, 2007), non-words (48 non-words obeying Italian phonotactics, DDE-2), and a text (MT-2, Cornoldi \& Colpo, 2011). For all tasks, accuracy (number of errors) and speed (number of syllables/second) were computed, according to test manuals. To examine reading comprehension abilities children were asked to read alone a story and then answer to 14 multiple-choice reading comprehension questions (MT-2, Cornoldi \& Colpo, 2011). The number of correct responses was scored.

2.3.2.2. Spelling. To evaluate spelling abilities from dictation three subtests by DDE-2 (Sartori et al., 2007) were used: words (the child was asked to write 48 words of different length and orthographical complexity), non-words (the child was asked to write 24 biyillabic or multisyllabic non-words obeying Italian phonotactics) and sentences (the child was asked to write 12 sentences with homophones). For all tasks, accuracy (number of errors) was computed, according to the manual.

2.3.2.3. Maths. A battery to investigate number and calculations abilities was administered to each child (AC-MT 6-11, Cornoldi, Lucangeli, \& Bellina, 2012). The battery provided the following indexes: number knowledge (numerosity judgment, transcoding and number sorting), written calculation, mental calculation, time (counting, mental calculation and written calculation), and problemsolving. Correct responses were scored for written calculation, number knowledge and problem-solving, errors for mental calculation, and seconds for time.

\subsection{Statistical analyses}

Statistical analyses were run using SPPS 23, and the significance level was set at 0.05 . Analyses of variance (ANOVAs) were run to compare VPT, SLD, and TD children in all skills; post-hoc Bonferroni comparisons were performed. In order to describe delays, the raw scores of VPT and SLD children were z-standardised $(M=0, S D=1)$ according to the TD children's mean and SD values.

To determine the profile of learning difficulties, the mean z-score was calculated for each learning area (reading: word, non-word and text speed and accuracy; spelling: word, non-word and sentence accuracy; maths: number knowledge, written calculation, mental calculation, time, problem-solving) and further classified as: impaired ( $\leq-2)$; at risk (between -2 and -1 ) and in average range $(\geq-1)$. Likelihood ratio analyses were run to compare the distribution of the three categories in each learning area among VPT, SLD and TD children and adjusted residuals were analyzed (adj residuals $>2$ were considered for significant differences). Only the impaired learning areas $(\leq-2)$ were further classified as isolated or in comorbidity.

\section{Results}

\subsection{IQ cognitive and language phenotypic markers}

Mean IQs of all groups fell within the normal range. A significant group effect was found in V-IQ, $F(2,167)=5.46 . p=.005$, $\eta_{p}{ }^{2}=.06$. VPT children had lower scores $(M=107.9, S D=13.2)$ than TD children $(M=115.6, S D=13.3$; Bonferroni, $p=.01)$, whereas SLD children did not significantly differ from TD peers $(M=109.5, S D=14.5)$. No significant group-related differences were found in C-IQ scores (VPT: $M=103.3, S D=11.2$; SLD: $M=102.6, S D=14.2$; TD: $M=107.3, S D=11.6$ ) and NV-IQ scores (VPT: $M=102.6, S D=12.6$; SLD: $M=98.6, S D=14.2$; TD: $M=102.4, S D=13.6$ ).

Concerning attention, digit span and semantic fluency, no differences were found among groups (Table 1). A significant group effect was found in phonological fluency, phonological processing, and RAN. VPT children had lower scores than TD children in phonological fluency $(p=.001)$. SLD children had lower scores than VPT and TD children in phonological processing (VPT: $p<.001$; TD: $p<.001$ ) and in RAN for both accuracy and time (VPT: $p=.001$, and $p=.024$; TD: $p=.008$, and $p<.001$ ). 
Table 1

The table summarizes means (and standard deviations, SDs) for cognitive and language phenotypic markers in children with specific learning disorders (SLD), very preterm children (VPT), and typically developing children (TD). F, p and partial eta-squared $\left(\eta_{p}{ }^{2}\right.$ ) values for ANOVAs are reported.

\begin{tabular}{|c|c|c|c|c|c|c|c|c|c|c|c|c|}
\hline & \multicolumn{3}{|c|}{ SLD children } & \multicolumn{3}{|c|}{ VPT children } & \multicolumn{3}{|c|}{ TD children } & \multicolumn{3}{|c|}{ ANOVA } \\
\hline & $N$ & $M$ & $S D$ & $N$ & $M$ & $S D$ & $N$ & $M$ & $S D$ & $F$ & $p$ & $\eta_{p}^{2}$ \\
\hline Attention & 28 & 106.7 & 20.7 & 37 & 108.3 & 16.7 & 105 & 107.0 & 16.3 & 0.10 & .901 & .01 \\
\hline Digit span & 28 & 12.7 & 2.6 & 37 & 13.6 & 2.5 & 105 & 14.1 & 2.8 & 2.71 & .070 & .03 \\
\hline Semantic fluency & 28 & 30.5 & 6.7 & 37 & 31.8 & 6.3 & 105 & 33.9 & 8.0 & 2.77 & .066 & .03 \\
\hline Phonological fluency & 28 & 18.2 & 6.2 & 37 & 15.9 & 4.8 & 105 & 19.9 & 5.9 & 6.86 & .001 & .08 \\
\hline Phonological processing & 28 & 42.4 & 3.6 & 37 & 46.7 & 2.4 & 105 & 47.5 & 2.8 & 34.29 & $<.001$ & .29 \\
\hline RAN (time) & 27 & 97.1 & 17.1 & 37 & 86.1 & 18.7 & 105 & 79.5 & 14.5 & 13.82 & $<.001$ & .14 \\
\hline RAN (accuracy) & 27 & 3.4 & 3.7 & 37 & 1.3 & 2.3 & 105 & 1.9 & 1.8 & 7.26 & .001 & .08 \\
\hline
\end{tabular}

Note: In bold the significant results. Correct responses for attention, digit span, semantic fluency, phonological fluency, and phonological processing; seconds for RAN (rapid automatized naming) time and errors for RAN accuracy.

\subsection{Literacy and numeracy skills}

A significant group effect was found in all reading tasks (Table 2). VPT children were slower than TD children (words: $p=.052$, tendency; text: $p=.003$ ) and SLD children were slower than VPT (words: $p<.001$; non-words: $p=.001$; text: $p<.001$ ) and TD children (for all tasks: $p<.001$ ). Fig. 1 shows the standardized differences (z scores) in VPT and SLD children. A significant group effect was also found in reading comprehension, since VPT children made more errors than TD peers $(p=.009)$ and SLD children made more errors than VPT $(p=.002)$ and TD peers $(p<.001)$.

A significant group effect was found in all spelling tasks (Table 2). VPT children made more errors than TD peers in non-words $(p=.013)$. SLD children committed more errors than VPT children in words and sentences $(p<.001)$ and more errors than TD peers in all tasks (words and sentences: $p<.001$; non-words: $p=.002$ ).

A significant group effect was found on number knowledge and maths (Table 3). VPT children showed less advanced skills than TD peers in number knowledge $(p=.021)$, written calculations $(p=.023)$ and problem-solving $(p=.049)$. SLD children showed less advanced skills than VPT and TD peers in all tasks ( $p<.001$ for all comparisons). Fig. 2 shows the standardized differences.

\subsection{Learning profiles and comorbidity}

The analysis of children's learning profiles (Table 4), revealed an unbalanced frequency distribution of participants among the impaired, at risk and average range categories. Adjusted residuals in reading skills, $\Lambda(4)=96.975 ; p<.001$, showed a higher than expected proportion of VPT children in the at risk category and of SLD children in the impaired category. Considering spelling and maths, no significant results were found for VPT children. By contrast, the frequency of SLD children in the impaired category was higher than expected for spelling, $\Lambda(4)=53.428 ; p<.001$, and maths, $\Lambda(4)=78.307 ; p<.001$.

Concerning comorbidity, $89.2 \%$ of the VPT children had no impairments, whereas only $10.7 \%$ of the SLD group had this profile

Table 2

The table summarizes means (and standard deviations, SDs) for literacy in children with specific learning disorders (SLD), very preterm children (VPT), and typically developing children (TD). F, p and partial eta-squared $\left(\eta_{p}{ }^{2}\right)$ values for ANOVAs are reported.

\begin{tabular}{|c|c|c|c|c|c|c|c|c|c|c|c|c|}
\hline & \multicolumn{3}{|c|}{ SLD children } & \multicolumn{3}{|c|}{ VPT children } & \multicolumn{3}{|c|}{ TD children } & \multicolumn{3}{|c|}{ ANOVA } \\
\hline & $N$ & $M$ & $S D$ & $N$ & $M$ & $S D$ & $N$ & $M$ & $S D$ & $F$ & $p$ & $\eta_{p}^{2}$ \\
\hline \multicolumn{13}{|l|}{ Reading speed } \\
\hline Words & 28 & 2.2 & 0.7 & 37 & 3.2 & 0.7 & 105 & 3.5 & 0.7 & 38.66 & $<.001$ & .32 \\
\hline Non-words & 28 & 1.4 & 0.4 & 37 & 1.9 & 0.5 & 105 & 2.1 & 0.7 & 16.49 & $<.001$ & .16 \\
\hline Text & 28 & 2.5 & 0.7 & 37 & 3.5 & 0.9 & 105 & 3.9 & 0.9 & 42.17 & $<.001$ & .34 \\
\hline \multicolumn{13}{|l|}{ Reading accuracy } \\
\hline Words & 28 & 9.1 & 7.3 & 37 & 2.6 & 2.9 & 105 & 1.6 & 1.6 & 52.41 & $<.001$ & .39 \\
\hline Non-words & 28 & 12.2 & 5.7 & 37 & 3.9 & 4.8 & 105 & 3.3 & 2.4 & 66.49 & $<.001$ & .44 \\
\hline Text & 28 & 9.0 & 6.2 & 37 & 2.5 & 1.9 & 105 & 2.2 & 1.7 & 59.71 & $<.001$ & .42 \\
\hline Reading Comprehension & 27 & 7.7 & 2.2 & 37 & 9.7 & 2.4 & 103 & 10.9 & 2.1 & 23.76 & $<.001$ & .22 \\
\hline \multicolumn{13}{|l|}{ Spelling } \\
\hline Words & 28 & 5.2 & 5.6 & 37 & 1.2 & 1.4 & 103 & 0.8 & 1.0 & 34.36 & $<.001$ & .29 \\
\hline Non-words & 28 & 5.1 & 3.1 & 37 & 4.5 & 2.3 & 103 & 3.2 & 2.3 & 8.86 & $<.001$ & .10 \\
\hline Sentences & 27 & 6.7 & 4.1 & 37 & 2.7 & 2.2 & 103 & 1.8 & 1.6 & 29.11 & $<.001$ & .37 \\
\hline
\end{tabular}

Note: In bold the significant results. Syllables/second for reading speed, errors for reading accuracy and spelling, correct responses for reading comprehension. 


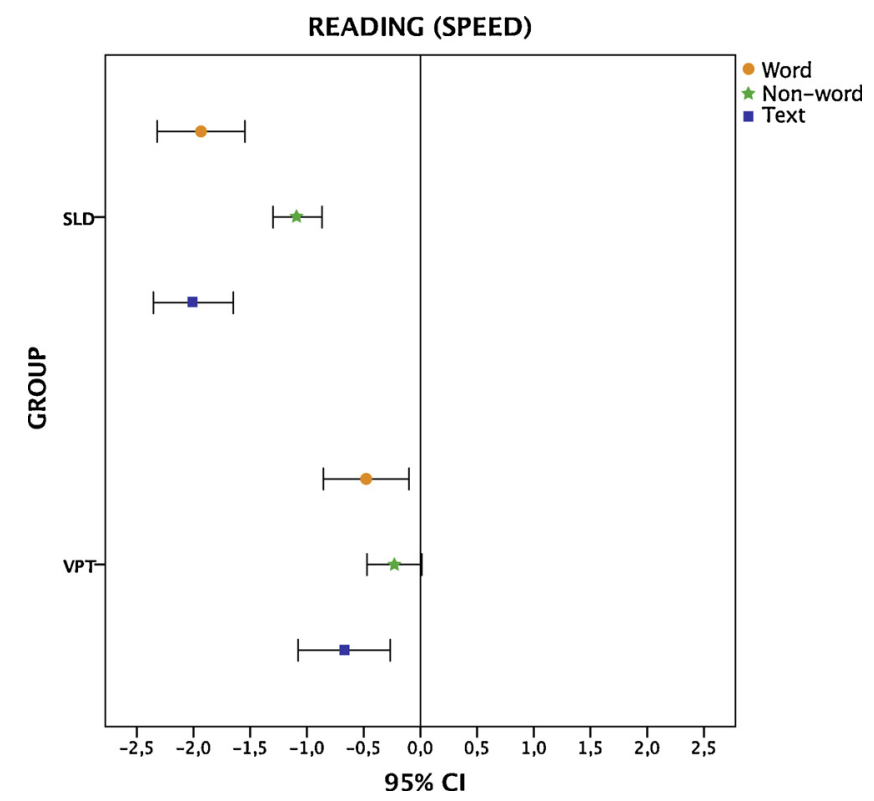

Fig. 1. Mean z-scores and 95\% confidence intervals for very preterm children (VPT) and children with specific learning disorders (SLD) with respect to the TD group on reading speed.

Note. The raw scores of VPT and SLD children were z-standardised according to the TD children's mean and SD values $(M=0, S D=1)$.

Table 3

The table summarizes means (and standard deviations, SDs) for numeracy skills and maths in children with specific learning disorders (SLD), very preterm children (VPT), and typically developing children (TD). F, p and partial eta-squared $\left(\eta_{p}{ }^{2}\right)$ values for ANOVAs are reported.

\begin{tabular}{|c|c|c|c|c|c|c|c|c|c|c|c|c|}
\hline & \multicolumn{3}{|c|}{ SLD children } & \multicolumn{3}{|c|}{ VPT children } & \multicolumn{3}{|c|}{ TD children } & \multicolumn{3}{|c|}{ ANOVA } \\
\hline & $N$ & $M$ & $S D$ & $N$ & $M$ & $S D$ & $N$ & $M$ & $S D$ & $F$ & $p$ & $\eta_{p}{ }^{2}$ \\
\hline Number knowledge & 28 & 15.4 & 3.4 & 37 & 18.3 & 2.8 & 105 & 19.7 & 2.3 & 29.56 & $<.001$ & .26 \\
\hline Written calculation & 28 & 4.1 & 2.1 & 37 & 6.3 & 1.3 & 105 & 7.0 & 1.0 & 51.84 & $<.001$ & .38 \\
\hline Mental calculation & 28 & 2.2 & 1.6 & 37 & 1.0 & 1.0 & 105 & 0.8 & 1.0 & 17.81 & $<.001$ & .17 \\
\hline Time & 27 & 192.1 & 57.5 & 37 & 115.3 & 33.8 & 105 & 104.0 & 32.5 & 58.83 & $<.001$ & .41 \\
\hline Problem-solving & 24 & 2.1 & 1.9 & 37 & 4.1 & 2.4 & 105 & 5.2 & 2.4 & 19.00 & $<.001$ & .19 \\
\hline
\end{tabular}

Note: In bold the significant results. Correct responses for number knowledge, written calculation and problem-solving. Errors for mental calculation. Seconds for Time.

(Table 5). The remaining VPT children showed a single-domain impairment (2.7\% for each domain), or reading and spelling deficits in comorbidity (2.7\%). In SLD children both single-domain impairments (28.6\% reading, $3.6 \%$ spelling, and $7.1 \%$ maths) and comorbidity of impairments (25\% reading and spelling; 3.6\% reading and maths, 3.6\% spelling and maths; $17.9 \%$ reading, spelling and maths) were found.

\section{Discussion}

The analysis of cognitive and linguistic phenotypic markers revealed some similarities (e.g., non verbal IQ, sustained attention, digit span, semantic fluency) among VPT children, children with SLD and TD peers as well as some differences (e.g., verbal IQ, phonological verbal fluency, phonological processing and RAN). As in previous studies, VPT children showed lower skills than TD peers in phonological verbal fluency (Mulder, Pitchford, Hagger, \& Marlow, 2009) and verbal IQ (Kerr-Wilson, Mackay, Smith, \& Pell, 2012), even if still identified as falling within the normal range (Anderson, Doyle, \& Victorian Infant Collaborative Study Group, 2003). SLD children showed lower scores in phenotypic markers of dyslexia and dyscalculia (phonological processing and RAN; Price \& Ansari, 2013; Snowling, 1998), but not in IQ scores, confirming an absence of general cognitive deficits (American Psychiatric Association, 2013).

Concerning academic achievements, lower scores in reading, spelling, and math abilities were found in SLD children as expected (Butterworth, Varma, \& Laurillard, 2011; Vellutino, Fletcher, Snowling, \& Scanlon, 2004). By contrast, the profile of VPT children was characterized by strengths and weaknesses. In each area of reading, spelling and maths, VPT in comparison to TD children showed adequate scores in some abilities besides some delayed abilities, even if delays were less severe than in children with SLD. The detailed description of impaired vs. unimpaired skills in VPT children were presented in the following paragraphs concerning 


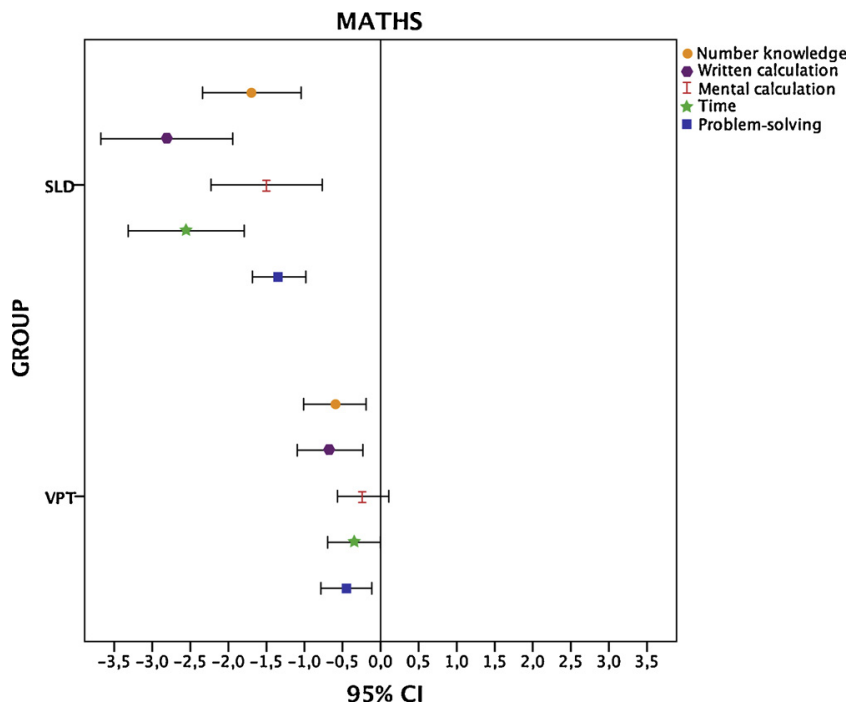

Fig. 2. Mean z-scores and 95\% confidence intervals for very preterm children (VPT) and children with specific learning disorders (SLD) with respect to the TD group on maths.

The raw scores of VPT and SLD children were z-standardised according to the TD children's mean and SD values $(M=0, S D=1)$.

Table 4

The table summarizes the percentage of children in each group as impaired ( $\leq-2$ SD), at risk (between -2 and -1 SD) or in the average range $(\geq-1 \mathrm{SD})$ in reading, spelling and maths.

\begin{tabular}{|c|c|c|c|c|c|c|c|c|c|}
\hline & \multicolumn{3}{|c|}{ SLD children } & \multicolumn{3}{|c|}{ VPT children } & \multicolumn{3}{|c|}{ TD children } \\
\hline & Impaired & At risk & Average & Impaired & At risk & Average & Impaired & At risk & Average \\
\hline Reading & $75 \%$ & $10.7 \%$ & $14.3 \%$ & $5.4 \%$ & $18.9 \%$ & $75.7 \%$ & $0 \%$ & $6.7 \%$ & $93.3 \%$ \\
\hline Spelling & $50 \%$ & $14.3 \%$ & $35.7 \%$ & $5.4 \%$ & $13.5 \%$ & $81.1 \%$ & $0 \%$ & $12.6 \%$ & $87.4 \%$ \\
\hline Maths & $32.1 \%$ & $42.9 \%$ & $25 \%$ & $2.7 \%$ & $10.8 \%$ & $86.5 \%$ & $0 \%$ & $1 \%$ & $99 \%$ \\
\hline
\end{tabular}

Table 5

The Table summarizes the prevalence of learning impairments and comorbidity in each group, with a cutoff of $\mathrm{z} \leq-2$.

\begin{tabular}{llc}
\hline & SLD children & VPT children \\
\hline No deficit & $3(10.7 \%)$ & $33(89.2 \%)$ \\
Reading only & $8(28.6 \%)$ & $1(2.7 \%)$ \\
Spelling only & $1(3.6 \%)$ & $1(2.7 \%)$ \\
Maths only & $2(7.1 \%)$ & $1(2.7 \%)$ \\
Reading and spelling & $7(25 \%)$ & $1(2.7 \%)$ \\
Reading and maths & $1(3.6 \%)$ & $0(0 \%)$ \\
Spelling and maths & $1(3.6 \%)$ & $0(0 \%)$ \\
Reading, spelling and maths & $5(17.9 \%)$ & $0(0 \%)$ \\
\hline
\end{tabular}

reading, spelling and maths.

The study identified new evidence for delays in decoding and reading comprehension at the end of primary school, previously described in VPT children exposed to English, i.e., an opaque and orthographically irregular language (Aarnoudse-Moens et al., 2009; Kovachy et al., 2015; Twilhaar, de Kieviet et al., 2018). In the present study these delays were found in VPT children exposed to a transparent and orthographically regular language, i.e. Italian. VPT children had less severe delays than SLD children, with mean scores falling in a normal range. However, residual delays were found in text reading speed, that we assume could be generalized to VPT children native speakers of other transparent languages. These findings suggest that difficulties in the consolidation of reading processes, previously found in Italian VPT children at the end of the second year of primary school (Guarini et al., 2010), persist up to the end of primary school without taking benefit from the contextual clues provided by text. These findings are consistent with difficulties found in reading comprehension that increase with age (Kovachy et al., 2015).

The present study showed that VPT birth also affected spelling skills, but with less severe difficulties than those described in English-speaking VPT children (Aarnoudse-Moens et al., 2009). In addition, whereas widespread delays were previously found in VPT Italian children at 8 years of age (including word, non-word and sentence spelling; Guarini et al., 2010), in the current study only a 
residual delay in non-word spelling was found at the end of primary school. Non-word spelling is a complex task, involving phonological and memory skills, and is considered a sensitive index of spelling difficulties in orthographically regular languages (Marinelli, Romani, Burani, \& Zoccolotti, 2015). We thus hypothesize that those VPT children exposed to regular languages maintain residual difficulties in complex spelling tasks.

Concerning maths, the present study showed that VPT children had less advanced skills than TD peers, as found in previous studies (Aarnoudse-Moens et al., 2009), but highlighted that only some skills were affected (number knowledge, written calculations, and problem-solving) with mean scores still falling in a normal range. Difficulties of VPT children in maths were widespread since both low-level skills (i.e., numerical knowledge) and higher-order skills (i.e., written calculations and problem-solving) were affected. With regard to low-level skills, i.e., number knowledge and numerical reasoning, previous studies have shown difficulties at preschool age (Aarnoudse-Moens et al., 2011) until 6 years, but no longer at 8 years (Guarini et al., 2014). However, our study suggests that delays persist at the end of primary school, thus new studies on this topic are needed. Concerning higher-order skills, i.e., application of mathematical concepts, in line with previous studies (Rose et al., 2011; Simms et al., 2013), our results suggest the persistence of a relevant difficulty until adolescence. Difficulties in mathematical problems might also depend on the weaknesses found in text comprehension that is fundamental for understanding math problems.

The description of learning profiles adds further information. As expected, a higher proportion of SLD children fell into the impaired category in all areas. By contrast, VPT children showed a higher proportion of risk in reading. The profile analysis showed that preterm birth increases the risk of learning delays, but not of disorders, bringing further and more generalized evidence to the hypothesis made by Jaekel and Wolke (2014) for math difficulties, who suggested that preterm birth does not increase the risk of dyscalculia, but lower gestational age is associated with a higher risk of mathematic impairments.

Concerning reading, spelling, and math impairments, many SLD children showed an isolated impairment (39.4\%) or comorbidity among impairments (50.1\%). By contrast, only $10.8 \%$ of the VPT sample had impairments; nevertheless, this percentage was higher than that of the Italian population (2.5-3.5\%; Consensus Conference, 2010). Our findings are in line with a study on ELGA children native speakers of an orthographically irregular language (Johnson, Wolke, Hennessy, \& Marlow, 2011), revealing a specific learning impairment in $14 \%$ of the sample. Our study also revealed that impairments in VPT children were equally distributed among reading, spelling, maths, and in reading and spelling comorbidity (2.7\% for each category), confirming the suggestion of Pritchard and colleagues (Pritchard, Bora, Austin, Levin, \& Woodward, 2014) that maths was more prominently delayed at 6 years, whereas reading and maths were similarly affected at 9 years. Indeed, our study, differed from others (Johnson et al., 2011, 2016; Taylor et al., 2009) and did not confirm that impairments in maths were more common than in reading at the end of primary school. Our findings could be explained by the fact that we included VPT children with no neurological damages or intellectual disabilities, whereas, in a previous study, math impairments were more frequently associated to cognitive deficits and lower gestational age (Johnson et al., 2016).

\subsection{Limitations}

Some limitations of the current study need to be taken into account. First, the sample size of the present study was adequate to detect medium to large effects, according to the previous literature on VPT children (Simms et al., 2013). However, since our study revealed small to medium effect in VPT children, a further study with a larger sample could be carried out in order to detect also subtle difficulties. A larger sample could be also useful to investigate differences in the academic achievement profile of VPT children in function of their neonatal immaturity. Secondly, measures of socio-economic status (SES) were not collected in the present study, even if the three samples were comparable for social background characteristics. The information of SES will be useful in further studies to better generalize the findings and understand the role of this factor in moderating the effect of preterm birth on academic achievement. Third, besides standardized tests, experimental tasks should also be used in future studies to assess online processes underlying the delayed skills. Fourth, this cross-sectional study investigated the profile of learning skills in VPT children at the end of primary school. Further longitudinal studies are needed to describe the developmental trajectories in adolescence and to confirm the pattern of our results over time. Indeed, as described by Thomas et al. (2009) "an optimal design for studying developmental disorders is to combine initial cross-sectional designs with longitudinal follow-up" (p. 336). In the end, in the present study we have compared the academic achievement profile of VPT children with SLD peers. However, since several studies have revealed delays also in attention and executive functions in VPT children (Mulder et al., 2009), further studies should be carried out in order to compare VPT children with children with attention deficit hyperactivity disorder, characterized by such difficulties in the attentional and executive function domains. The comparison with different populations with neurodevelopmental disorders will be very useful to understand the developmental trajectory of VPT children.

\section{Conclusions}

The present study describes the learning profile of VPT children, pointing out two main considerations. First, according to a neuroconstructivist approach, it suggests that biological and socio-environmental constraints associated with preterm birth lead to an atypical development with residual delays in reading, spelling and maths at the end of primary school. However, this atypical academic achievement profile in VPT children cannot be considered similar to that of SLD children, since delays were less widespread (involving only some learning abilities, i.e., reading text speed, reading comprehension, non-word spelling, number knowledge, written calculations and problem-solving) and less severe (i.e., mean scores comprised within -1 SD). In addition, phenotypic markers were different between the two populations since VPT children showed lower skills than TD peers in phonological verbal 
fluency and verbal IQ, whereas SLD children showed lower scores in phonological processing and RAN. In the end, compared to TD children, a higher rate of SLD children fell into the impaired category, with a high percentage of comorbidity among learning areas, whereas VPT children showed a higher proportion of at-risk performance in reading. Considering the atypical and specific academic achievement profile of VPT children at the end of primary school, follow-up programs and effective interventions on delayed abilities should be proposed for the preterm population.

\section{Funding source}

All phases of this study were supported by University of Bologna (FARB 2012 'Processi di lettura in bambini nati pretermine, dislessici e normolettori'. Coordinator: Annalisa Guarini).

\section{Conflict of interest}

No conflicts of interest to disclose.

\section{Acknowledgements}

We are grateful to the parents and their infants for the participation in the research. We express our gratitude to Felicia Roga, Mariangela D’Antuono, Nicole Trambagioli, Margherita Barbieri, Luca Bernabini, Veronica Zavagli, Silvia Savini for helping in data collection and coding. We are also grateful to Prof. Phillip Slee (Flinders University) for English language editing.

\section{Appendix A. Supplementary data} 001.

Supplementary material related to this article can be found, in the online version, at doi:https://doi.org/10.1016/j.ridd.2019.02.

\section{References}

Aarnoudse-Moens, C. S. H., Oosterlaan, J., Duivenvoorden, H. J., van Goudoever, J. B., \& Weisglas-Kuperus, N. (2011). Development of preschool and academic skills in children born very preterm. The Journal of Pediatrics, 158(1), 51-56.

Aarnoudse-Moens, C. S. H., Weisglas-Kuperus, N., van Goudoever, J. B., \& Oosterlaan, J. (2009). Meta-analysis of neurobehavioral outcomes in very preterm and/or very low birth weight children. Pediatrics, 124(2), 717-728.

American Psychiatric Association (2013). Diagnostic and statistical manual of mental disorders (DSM-5 ${ }^{\circledR}$ ). American Psychiatric Pub.

Anderson, P., Doyle, L. W., \& Victorian Infant Collaborative Study Group (2003). Neurobehavioral outcomes of school-age children born extremely low birth weight or very preterm in the 1990s. JAMA, 289(24), 3264-3272.

Andersson, U. (2010). Skill development in different components of arithmetic and basic cognitive functions: Findings from a 3-year longitudinal study of children with different types of learning difficulties. Journal of Educational Psychology, 102(1), 115.

Bonifacci, P., \& Nori, R. (2016). KBIT-2. Kaufman Brief Intelligence Test Second Edition. Contributo alla Taratura Italiana [Contribution to Italian Standardization]. Florence, Italy: Giunti-OS.

Butterworth, B., Varma, S., \& Laurillard, D. (2011). Dyscalculia: From brain to education. Science, 332(6033), $1049-1053$.

Chyi, L. J., Lee, H. C., Hintz, S. R., Gould, J. B., \& Sutcliffe, T. L. (2008). School outcomes of late preterm infants: Special needs and challenges for infants born at 32 to 36 weeks gestation. The Journal of Pediatrics, 153(1), 25-31.

Consensus Conference (2010). I Disturbi Specifici dell'Apprendimento [Specific Learning Disorders]. Rome: Istituto Superiore di Sanità 6-7 December 2010.

Cornoldi, C., \& Colpo, G. (2011). Prove di Lettura MT-2 per la Scuola Primaria [MT-2 Tasks for the Assessment of Reading in Primary School]. Florence, Italy: Giunti-OS.

Cornoldi, C., Lucangeli, D., \& Bellina, M. (2012). AC-MT 6-11. Test di Valutazione delle Abilità di Calcolo e Soluzione dei Problemi. Gruppo MT [AC-MT 6-11. Test for the Assessment of Calculation Abilities and Problem Solving]. Trento, Italy: Edizioni Erickson.

D’Souza, D., Booth, R., Connolly, M., Happé, F., \& Karmiloff-Smith, A. (2016). Rethinking the concepts of "local or global processors": evidence from Williams syndrome, Down syndrome, and Autism Spectrum Disorders. Developmental Science, 19(3), 452-468.

De Luca, M., Di Filippo, G., Judica, A., Spinelli, D., \& Zoccolotti, P. (2005). Test di Denominazione Rapida e Ricerca Visiva di Colori, Figure e Numeri[Test of Rapid Naming and visual Search of Colors, Pictures and Digits]. Rome, Italy: IRCCS Santa Lucia Foundation.

Ghelani, K., Sidhu, R., Jain, U., \& Tannock, R. (2004). Reading comprehension and reading related abilities in adolescents with reading disabilities and attention-deficit/hyperactivity disorder. Dyslexia, 10(4), 364-384.

Guarini, A., Sansavini, A., Fabbri, M., Alessandroni, R., Faldella, G., \& Karmiloff-Smith, A. (2014). Basic numerical processes in very preterm children: A critical transition from preschool to school age. Early Human Development, 90(3), 103-111.

Guarini, A., Sansavini, A., Fabbri, C., Savini, S., Alessandroni, R., Faldella, G., et al. (2010). Long-term effects of preterm birth on language and literacy at eight years. Journal of Child Language, 37(4), 865-885.

Jaekel, J., \& Wolke, D. (2014). Preterm birth and dyscalculia. The Journal of Pediatrics, 164(6), 1327-1332.

Johnson, S., Strauss, V., Gilmore, C., Jaekel, J., Marlow, N., \& Wolke, D. (2016). Learning disabilities among extremely preterm children without neurosensory impairment: Comorbidity, neuropsychological profiles and scholastic outcomes. Early Human Development, 103, 69-75.

Johnson, S., Wolke, D., Hennessy, E., \& Marlow, N. (2011). Educational outcomes in extremely preterm children: Neuropsychological correlates and predictors of attainment. Developmental Neuropsychology, 36(1), 74-95.

Kerr-Wilson, C. O., Mackay, D. F., Smith, G. C. S., \& Pell, J. P. (2012). Meta-analysis of the association between preterm delivery and intelligence. Journal of Public Health, 34(2), 209-216.

Kovachy, V. N., Adams, J. N., Tamaresis, J. S., \& Feldman, H. M. (2015). Reading abilities in school-aged preterm children: a review and meta-analysis. Developmental Medicine \& Child Neurology, 57(5), 410-419.

Loe, I. M., Luna, B., Bledsoe, I. O., Yeom, K. W., Fritz, B. L., \& Feldman, H. M. (2012). Oculomotor assessments of executive function in preterm children. The Journal of Pediatrics, 161(3), 427-433.

Marinelli, C. V., Romani, C., Burani, C., \& Zoccolotti, P. (2015). Spelling acquisition in English and Italian: A cross-linguistic study. Frontiers in Psychology, 6, 1843.

Moreira, R. S., Magalhães, L. C., \& Alves, C. R. (2014). Effect of preterm birth on motor development, behavior, and school performance of school-age children: A systematic review. Jornal de Pediatria, 90(2), 119-134.

Mulder, H., Pitchford, N. J., Hagger, M. S., \& Marlow, N. (2009). Development of executive function and attention in preterm children: A systematic review. 
Developmental Neuropsychology, 34(4), 393-421.

Orsini, A., \& Picone, L. (2006). WISC-III: Contributo alla Taratura Italiana [Contribution to Italian Standardization]. Florence, Italy: Giunti-OS.

Price, G. R., \& Ansari, D. (2013). Dyscalculia: Characteristics, causes, and treatments. Numeracy, 6(1), 2.

Pritchard, V. E., Bora, S., Austin, N. C., Levin, K. J., \& Woodward, L. J. (2014). Identifying very preterm children at educational risk using a school readiness framework. Pediatrics, 134(3), e825-e832.

Pritchard, V. E., Clark, C. A., Liberty, K., Champion, P. R., Wilson, K., \& Woodward, L. J. (2009). Early school-based learning difficulties in children born very preterm. Early Human Development, 85(4), 215-224.

Roid, G. H., \& Miller, L. J. (2002). Leiter International Performance Scale—Revised (Leiter-R) (Italian Version). Florence, Italy: Giunti-OS.

Rose, S. A., Feldman, J. F., \& Jankowski, J. J. (2011). Modeling a cascade of effects: The role of speed and executive functioning in preterm/full-term differences in academic achievement. Developmental Science, 14(5), 1161-1175.

Sansavini, A., Guarini, A., \& Caselli, M. C. (2011). Preterm birth: Neuropsychological profiles and atypical developmental pathways. Developmental Disabilities Research Reviews, 17(2), 102-113.

Sartori, G., Job, R., \& Tressoldi, P. E. (2007). DDE-2. Batteria per la Valutazione della Dislessia e Disortografia Evolutiva-2 [DDE-2. Battery for the Assessment of Developmental Dyslexia and Dysorthographia-2]. Florence, Italy: Giunti-OS.

Shah, P., Kaciroti, N., Richards, B., Oh, W., \& Lumeng, J. C. (2016). Developmental outcomes of late preterm infants from infancy to kindergarten. Pediatrics, 138(2), e20153496.

Simms, V., Cragg, L., Gilmore, C., Marlow, N., \& Johnson, S. (2013). Mathematics difficulties in children born very preterm: Current research and future directions. Archives of Disease in Childhood-Fetal and Neonatal Edition, 98, 457-463.

Simms, V., Gilmore, C., Cragg, L., Clayton, S., Marlow, N., \& Johnson, S. (2015). Nature and origins of mathematics difficulties in very preterm children: A different etiology than developmental dyscalculia. Pediatric Research, 77(2), 389-395.

Snowling, M. (1998). Dyslexia as a phonological deficit: Evidence and implications. Child Psychology and Psychiatry Review, 3(1), 4-11.

Taylor, H. G., Espy, K. A., \& Anderson, P. J. (2009). Mathematics deficiencies in children with very low birth weight or very preterm birth. Developmental Disabilities Research Reviews, 15(1), 52-59.

Taylor, R., Pascoe, L., Scratch, S., Doyle, L. W., Anderson, P., \& Roberts, G. (2016). A simple screen performed at school entry can predict academic under-achievement at age seven in children born very preterm. Journal of Paediatrics and Child Health, 52(7), 759-764.

Thomas, M. S. C., Annaz, D., Ansari, D., Scerif, G., Jarrold, C., \& Karmiloff-Smith, A. (2009). Using developmental trajectories to understand genetic disorders. Journal of Speech and Hearing Research, 52, 336-358.

Twilhaar, E. S., de Kieviet, J. F., Aarnoudse-Moens, C. S., van Elburg, R. M., \& Oosterlaan, J. (2018). Academic performance of children born preterm: A meta-analysis and meta-regression. Archives of Disease in Childhood-Fetal and Neonatal Edition, 103, F322-F330.

Twilhaar, E. S., Wade, R. M., De Kieviet, J. F., Van Goudoever, J. B., Van Elburg, R. M., \& Oosterlaan, J. (2018). Cognitive outcomes of children born extremely or very preterm since the 1990s and associated risk factors: A meta-analysis and meta-regression. JAMA, 172(4), 361-367.

Urgesi, C., Campanella, F., \& Fabbro, F. (2011). NEPSY-II.Contributo alla Taratura Italiana [Contribution to Italian Standardization]. Florence, Italy: Giunti-OS.

Vellutino, F. R., Fletcher, J. M., Snowling, M. J., \& Scanlon, D. M. (2004). Specific reading disability (dyslexia): What have we learned in the past four decades? Journal of Child Psychology and Psychiatry, 45(1), 2-40.

World Health Organization, International statistical classification of diseases and related health problems, 10th revision, https://icd.who.int/browse10/2016/en, 2016. 